\title{
Federalismo realocativo: sobre-representação legislativa e gastos públicos no hemisfério ocidental
}

\author{
Edward L. Gibson \\ Northwestern University, EUA e Centro de \\ Investigaciones y Docencia Economica, México \\ Ernesto F. Calvo \\ Candidato a PhD, Northwestern University \\ Tulia G. Falleti \\ Candidata a PhD, Northwestern University
}

\begin{abstract}
Resumo
Este artigo trata da economia política do federalismo e a questão básica examinada é se a sobre-representação de territórios (estados e províncias) nas legislaturas nacionais dos sistemas federais afeta a distribuição territorial dos gastos públicos dos governos federais. A hipótese testada é que afeta e a sobre-representação territorial produz uma distorção dos gastos federais que beneficia as populações que vivem em territórios sobrerepresentados. Para captar essa conexão entre sobre-representação territorial e a distribuição não-proporcional de fundos públicos foi introduzida uma distinção conceitual: os países em que essa conexão existe são identificados como casos de federalismo realocativo, enquanto que os países com padrões territoriais de gastos públicos que são proporcionais à população são identificados como casos de federalismo proporcional. Os argumentos baseiam-se em dados subnacionais dos quatro maiores países federais do hemisfério ocidental: Estados Unidos, Brasil, México e Argentina.
\end{abstract}

Palavras-chave: federalismo, representação política, gastos públicos, território, sistema proporcional

\section{Abstract}

This article is an inquiry into the political economy of federalism and the basic question explored is, does the overrepresentation of territories (states or provinces) in national legislatures of federal systems affect the territorial distribution of public spending by federal governments? The hypothesis to be tested is that it does, and that territorial overrepresentation produces a distortion of federal spending which benefits the population that live in overrepresented territories. To capture this connection it was introduced a conceptual distinction between territorial overrepresentation and the non-proportional distribution of public funds: countries where this connection exists are identified as cases of reallocative federalism, whereas countries with territorial patterns of public spending that are proportional to population are identified as cases of proportional federalism. The evidence is drawn from subnational-level data (at the provincial/state level) from the Western Hemisphere's four largest federal countries, the United States of America, Brazil, Mexico, and Argentina. benefits populations living in overrepresented territories.

Keywords: federalism, political representation, public expenditures, territory, proporcional system 


\section{Introdução}

As características institucionais dos sistemas federativos causam um impacto independente na política e nas políticas públicas? Durante muito tempo, o debate esteve de alguma forma fechado. A sugestão de William Riker de que o federalismo e suas instituições não causavam impacto significativo sobre as políticas públicas, de um modo geral, não foi questionada nas três décadas seguintes a que ele manifestou-se pela primeira vez sobre esse tema ${ }^{1}$. Porém, essa afirmação vem passando recentemente por um reexame. Na coletânea em que este artigo está publicado originalmente ${ }^{2}$ Alfred Stepan questiona a posição de Riker de modo explícito e outros colaboradores (Main waring e Samuels, Penfold Becerra e Ochoa Reza) oferecem críticas implícitas ao ceticismo de Riker em relação aos efeitos independentes das instituições federais sobre os resultados políticos. Os artigos desses autores atacam a questão em várias perspectivas, mas a linha comum que os une remonta à relação entre os traços institucionais dos sistemas federativos e as assimetrias subjacentes dos países federativos. Todos caracterizam-se internamente, de várias maneiras, pela assimetria: há assimetrias em população, tamanho e poder econômico entre os territórios que constituem uma união federal. As instituições federais interagem com essas assimetrias subjacentes concedendo determinados direitos políticos, obrigações e representação nos organismos do governo nacional às unidades constituintes da federação. Em alguns casos, essas instituições concordam com as assimetrias e em outros, as compensam. As instituições federais também contêm suas próprias assimetrias: elas existem entre os órgãos governamentais da federação, entre câmaras alta e baixa das legislaturas nacionais, ou entre prerrogativas constitucionais atribuídas a governos centrais e subnacionais (ou, com freqüência, entre governos subnacionais). O desenho das instituições federais tem assim implicações para o modo como o poder é distribuído entre atores fundamentais em um sistema federativo. Elas conformam (e reformam) a distribuição espacial de poder entre atores com base territorial e a distribuição institucional do poder entre atores localizados em diferentes "níveis" da sociedade federal. Em conseqüência, pode-se esperar que deliberações essenciais, da estruturação de padrões de representação política à distribuição de bens e recursos públicos, sejam, ao menos em parte, determinadas pelos variados traços institucionais observáveis nos sistemas federais.

Este artigo contribui para essa pesquisa explorando o impacto de um traço institucional que, embora intrínseco à maioria dos sistemas federativos, recebeu

\footnotetext{
${ }^{1}$ Ver Riker, 1964. Seus argumentos são aprofundados em publicações posteriores como Riker (1975; 1987).

${ }^{2}$ Trabalho ainda em organização: Edward Gibson (ed). 2003. Federalismo Latim America in Comparative Perspective, Johns Hopkins University Press.
} 
relativamente pouca atenção da literatura sobre a política e a economia política do federalismo: a sobre-representação de unidades territoriais subnacionais (províncias ou estados) nas legislaturas nacionais. Todos os sistemas federais refletem internamente as tensões entre normas de representação territorial e normas de representação da população (ou dos cidadãos). Cada um deles reflete, na estrutura de sua constituição, um equilíbrio historicamente determinado entre essas normas. Os sistemas federais existentes em todo o mundo exibem variações significativas na primazia de uma norma sobre a outra ${ }^{3}$.

A questão básica que será examinada neste trabalho é: a sobrerepresentação de territórios (estados e províncias) nas legislaturas nacionais dos sistemas federais afeta a distribuição territorial dos gastos públicos dos governos federais? A hipótese a ser testada é que afeta sim e que a sobre-representação territorial produz uma distorção dos gastos federais que beneficia as populações que vivem nos territórios sobre-representados ${ }^{4}$. Introduzimos também uma distinção conceitual para captar essa conexão entre sobre-representação territorial e a distribuição não-proporcional de fundos públicos: os países em que essa conexão existe são identificados como casos de federalismo realocativo, enquanto os países com padrões territoriais de gastos públicos proporcionais à população são identificados como casos de federalismo proporcional ${ }^{5}$. Este artigo é portanto, uma investigação sobre a economia política do federalismo. Examinamos em que medida as características institucionais dos países federais moldam a distribuição dos recursos econômicos entre suas unidades territoriais constituintes. Nossos argumentos baseiam-se em dados subnacionais dos quatro maiores países federais do hemisfério ocidental: Estados Unidos, Brasil, México e Argentina.

A análise está dividida em três partes. Na primeira, oferecemos dados descritivos que comparam a sobre-representação nas legislaturas dos quatro países, contrastando a sobre-representação nos senados e nas câmaras baixas. Oferecemos também dados comparativos das distorções regionais em gastos públicos em cada um dos países. Embora, na teoria, as câmaras baixas devessem representar as populações, e não territórios, os quatro casos exibem enormes

\footnotetext{
${ }^{3}$ Ver Stepan (2001) e Samuels e Snyder (2001) para provas quantitativas dessas variações.

${ }^{4}$ Uma nota semântica: utilizamos em todo o artigo o termo "sobre-representação, em vez de malapportionment [má distribuição, desproporção], de uso mais comum na literatura. Assim o fazemos para evitar as conotações negativas dessa palavra. Não pretendemos sustentar que a sobre-representação territorial é uma característica "ruim" dos sistemas federais. $\mathrm{Na}$ verdade, ela pode ser benéfica para a estabilidade e a integridade territorial desse sistemas, em particular daqueles com assimetrias econômicas e demográficas significativas entre suas unidades subnacionais. A sobre-representação territorial pode funcionar como um mecanismo compensatório entre unidades desiguais, proporcionando alavancagem política a províncias ou estados fracos que de outra forma não a teriam, tendo em vista a influência econômica ou demográfica dos estados ou províncias dominantes.

${ }^{5}$ Os programas de partilha de receita federal têm, por definição, uma função redistributiva, pois ao alocar fundos proporcionalmente à população, eles efetuam uma redistribuição das receitas fiscais nacionais dos estados mais ricos para os mais pobres. Adotamos assim a expressão "federalismo realocativo" para indicar os casos em que a sobre-representação promove uma alocação regional de fundos públicos que desvia da norma da proporcionalidade.
} 
Federalismo realocativo: Sobre-representação legislativa e gastos públicos no hemisfério ocidental

variações na adesão a essa norma: os Estados Unidos e o México tendem a atribuir assentos aos estados em proporção à sua população; o Brasil e a Argentina sobrerepresentam significativamente vários estados na câmara baixa. Nesse último grupo, portanto, existe uma estrutura dual de sobre-representação territorial, com a alocação regional de assentos da câmara somando-se à sobre-representação inerente ao papel do senado como arena da representação territorial. A segunda seção analisa as relações acima mencionadas por meio de dados agrupados de nosso grupo de países. Sustentamos que a sobre-representação na câmara baixa causa um impacto maior sobre as distorções dos gastos federais do que todas as outras variáveis (inclusive a sobre-representação no senado) e explica as diferenças entre os federalismos "realocativos" de Brasil e Argentina e os federalismos "proporcionais" de México e Estados Unidos. Na parte final, oferecemos uma perspectiva mais aprofundada por meio de um estudo de caso de gastos públicos e montagem de coalizão eleitoral na Argentina, um dos nossos casos de federalismo "realocativo".

\section{Sobre-representação e partilha de receitas: padrões nos Estados Unidos, México, Brasil e Argentina}

Os países federativos aqui analisados sobre-representam os estados em suas legislaturas nacionais em graus variados. Todos possuem senados nacionais onde esta sobre-representação territorial está deliberadamente incluída na alocação de seus assentos. Porém, não no mesmo grau. Como mostra a Tabela $1^{6}$ nos senados brasileiro, americano e argentino a sobre-representação dos estados é consideravelmente maior do que no senado mexicano ${ }^{7}$.

\footnotetext{
${ }^{6}$ A sobre-representação no senado e na câmara baixa é medida por um índice que é a razão da porcentagem de assentos de um estado para sua porcentagem da população nacional. Uma razão de 1 significa que a porcentagem de assentos é igual à porcentagem da população nacional.

${ }^{7}$ E ela é provavelmente ainda maior do que esses dados indicam, pois a partir de 1996, o Senado Mexicano tem três senadores por estado e 32 senadores eleitos com base na representação proporcional, abrandando assim a natureza territorial de sua representação. Os senadores eleitos por representação proporcional não estão incluídos nos dados aqui apresentados. Em uma versão posterior deste trabalho, examinaremos se eles podem ser incorporados às medidas usadas aqui. Para uma recente discussão sugestiva do federalismo mexicano, ver Marván, 1997.
} 


\section{Tabela 1}

Sobre-representação e gastos públicos

\section{Variáveis descritivas}

\begin{tabular}{|c|c|c|c|c|c|c|c|}
\hline & País & $\mathbf{N}$ & Amplitude & Mínimo & Máximo & Média & $\begin{array}{l}\text { Desvio } \\
\text { Padrão } \\
\end{array}$ \\
\hline \multirow[t]{4}{*}{$\begin{array}{l}\text { Senado } \\
\text { Sobre-rep: }\end{array}$} & Argentina & 24 & 19.73 & 0.11 & 19.84 & 3.44 & 4.07 \\
\hline & Brasil & 27 & 25.8 & 0.18 & 25.98 & 3.93 & 6.1 \\
\hline & U.S.A. & 50 & 21.89 & 0.33 & 22.22 & 5.24 & 5.3 \\
\hline & México & 32 & 7.8 & 0.26 & 8.03 & 1.96 & 1.8 \\
\hline \multirow[t]{4}{*}{$\begin{array}{l}\text { Câmara } \\
\text { sobre-rep: }\end{array}$} & Argentina & 24 & & & 9.59 & 1.85 & 1.8 \\
\hline & Brasil & 27 & 9.89 & 0.63 & 10.52 & 1.92 & 2.31 \\
\hline & U.S.A. & 50 & 0.56 & 0.72 & 1.28 & 1 & 0.086 \\
\hline & México & 32 & 0.79 & 0.91 & 1.7 & 1.04 & 0.137 \\
\hline \multirow[t]{4}{*}{$\begin{array}{l}\text { Razão ratio } \\
\text { Fundos }\end{array}$} & Argentina & 24 & 6.44 & 0.58 & 7.02 & 2.22 & 1.6 \\
\hline & Brasil & 27 & 17.25 & 0.05 & 17.3 & 3.25 & 4.68 \\
\hline & U.S.A. & 50 & 1.53 & 0.65 & 2.19 & 1.06 & 0.3 \\
\hline & México & 32 & 1.65 & 0.69 & 2.35 & 1.08 & 0.37 \\
\hline
\end{tabular}

Nota: "Senado Sobre-rep"e "Câmara sobre rep"=Razão entre participação percentual do estado no total de assentos e participação percentual do estado na população nacional. O escore de 1 significa que a alocação de assentos é proporcional à população.

"Fundo Ratio"=razão entre a participação percentual do estado nas transferências federais e a participação percentual dos estados na população. Um escore de 1 significa que os fundos recebidos são proporcionais à população

Os dados mostram também que existe uma considerável distorção nos três primeiros casos. Todos têm grandes amplitudes entre o estado mais subrepresentado e os mais sobre-representados, e suas razões médias são pelo menos três vezes aquelas que refletiriam uma representação proporcional. Ademais, os três países apresentam diferenças imensas entre a quantidade de votos exigida para eleger um senador nos estados mais sub-representados e nos mais sobrerepresentados. Na Argentina, um voto na Terra do Fogo é igual a 180 votos em Buenos Aires. No Brasil, um voto em Roraima equivale a 144 votos em São Paulo, e nos Estados Unidos, um voto no Wyoming equivale a 67 votos na Califórnia. Em contraste, no México, cujo senado também aloca assentos de modo desproporcional entre os estados, um voto na Baixa Califórnia equivale a 31 votos 
no estado do México ${ }^{8}$.

A Tabela 1 mostra também o grau de sobre-representação presente nas câmaras baixas desses países. Aqui o resultado revela uma divisão dos casos em dois grupos. Brasil e Argentina demonstram um desvio notável da norma da proporcionalidade na alocação regional dos assentos da câmara baixa aos estados. Ambos exibem uma amplitude substancial entre o mais sub-representado e os estados sobre-representados (substancial para um organismo supostamente proporcional) e a razão média da participação em assentos para a participação da população nestes países é de quase 2 para 1 . Em contraste, as câmaras baixas mexicana e americana são muito proporcionais na alocação de assentos entre os estados. Para ambas, a razão média é de 1 para $1^{9}$.

Por fim, os dados da Tabela 1 proporcionam medidas de desvio (da proporcionalidade) na distribuição de fundos de receita compartilhada alocados pelo governo central aos estados. Uma vez mais, os quatro casos se separam em dois grupos opostos. Argentina e Brasil revelam uma distorção regional consideravelmente maior do que México e Estados Unidos ${ }^{10}$. O Brasil, em especial, apresenta a maior mostra distorção maior. A amplitude entre o estado mais beneficiado e o menos beneficiado é quase três vezes a de seu concorrente mais próximo, a Argentina. Contudo, a amplitude da Argentina é, de outro lado, quatro vezes maior do que a mexicana e americana, cujas razões médias de participação nos fundos federais e a participação na população estão perto da proporcionalidade completa.

Em resumo, do ponto de vista da economia política, Brasil e Argentina apresentam casos de federalismo realocativo, enquanto México e Estados Unidos se aproximam do modelo do federalismo proporcional. O que é responsável pelas distorções regionais dos gastos federais e quais fatores explicam melhor as diferenças entre federalismo proporcional e realocativo? Tentamos responder a essas questões na seção seguinte ao mesmo tempo em que oferecemos um quadro das associações fundamentais entre sobre-representação e condições socioeconômicas das unidades territoriais subnacionais.

\footnotetext{
${ }^{8}$ Em sua contribuição ao volume em que este artigo foi publicado originalmente, Alfred Stepan usa uma única medida para classificar os sistemas federais, o "coeficiente gini de desigualdade representacional". Ele classifica os senados desses países do mais ao menos sobre-representativo na seguinte ordem: Argentina, Brasil, Estados Unidos e México.

${ }^{9}$ A Câmara de Deputados mexicana combina deputados eleitos por distritos de um único membro de cada estado com deputados eleitos por representação proporcional em cinco distritos multi-estaduais. Trezentos deputados representam os distritos comuns e duzentos os outros. Por enquanto, os dados apresentados aqui incluem apenas os trezentos deputados de distritos estaduais. Para detalhes sobre o sistema eleitoral mexicano, ver Instituto Federal Electoral (1997).

${ }^{10}$ A medida de distorção para gastos federais é semelhante à da sobre-representação no senado e na câmara. É uma razão da cota de fundos federais recebidos pelo estado para sua participação na população nacional. Um coeficiente de 1 indica uma alocação de fundos completamente proporcional.
} 


\section{Sobre-representação e gastos públicos: comparações entre dados agrupados}

A Tabela 2 apresenta correlações individuais entre medidas de sobrerepresentação e as variáveis socioeconômicas e de gastos públicos selecionadas. Como dito anteriormente, elas são geradas por dados agrupados dos 133 estados dos quatro países em estudo. Entre essas variáveis, "senover" e "houseover" são as medidas de sobre-representação anteriormente apresentadas. Do mesmo modo, "fundratio" é a razão, também apresentada na seção anterior, da cota dos estados nas transferências federais não-discricionárias para sua participação percentual na população nacional. "Discratio" é outra medida de distorção de gastos regionais e representa transferências discricionárias do governo federal recebidas pelos estados.

Tabela $2^{11}$

Sobre-representação, variáveis socioeconômicas e de gastos públicos

\begin{tabular}{|c|c|c|c|c|}
\hline Variável & Houseover & Senover & Fundratio & Discratio \\
\hline Houseover & 1.000 & $0.638^{* *}$ & $0.824^{\star *}$ & $0.820^{* *}$ \\
\hline Senover & 0.638 & 1.000 & $0.529^{\star *}$ & $0.352^{\star *}$ \\
\hline Fundratio & $0.824^{\star *}$ & $0.529^{* *}$ & 1.000 & 0.907 \\
\hline Discratio & $0.820^{\star *}$ & $0.352^{* *}$ & $0.907^{\star *}$ & 1.000 \\
\hline Perlocal & $-0.315^{\star *}$ & -0.023 & $-0.334^{* *}$ & $-0.256^{* *}$ \\
\hline Pubemp & $0.530^{* *}$ & $0.262^{* *}$ & $0.386^{* *}$ & $0.615^{\star *}$ \\
\hline Pobreza & 0.069 & -0.088 & $0.211^{*}$ & -0.136 \\
\hline Renda & $-0.195^{\star}$ & 0.163 & $-0.258^{\star *}$ & -0.025 \\
\hline
\end{tabular}

** Correlação significativa no nível 0.01 (bicaudal)

* Correlação significativa no nível 0.05 (bicaudal)

$\mathrm{N}=133$, para todos os coeficientes de correlação, exceto aqueles com Discrat ( $\mathrm{N}=105$, Brasil não incluído).

Os dados da Tabela 2 mostram correlações positivas muito fortes entre sobre-representação no senado e na câmara e as duas medidas de distorção de

\footnotetext{
${ }^{11}$ A variável "pubemp" representa os empregados do setor público estadual do Brasil, Argentina e Estados Unidos, e os funcionários públicos estaduais e municipais do México. A variável "pobreza" representa a porcentagem da população que vive abaixo da linha oficial de pobreza nos Estados Unidos, e usas um proxy para pobreza, porcentagem da população que é analfabeta, para Brasil, Argentina e México (que apresenta alta correlação com os índices de pobreza que temos disponíveis). "Renda" representa rendas medidas mensais por família medidas em dólares americanos. Todos os dados foram tirados de publicações oficiais e sites da internet. Os dados para os EUA foram tirados dos U.S. Census Bureau Statistical Abstracts para 1994 e 1997. Os dados para a Argentina são do INDEC 1997 e do Ministerio de Economía y Obras y Servicios Públicos (1994). Os dados mexicanos são do INEGI, 1995. Os brasileiros vêm do IBGE (http://www.ibge.gov.br) e do Ministério de Fazenda (http://www.fazenda.gov.br) bem como do Ministério da Administração Federal e Reforma do Estado (1997).
} 
gastos. Mostram ainda que os coeficientes de correlação registrados para a sobrerepresentação na câmara são consideravelmente maiores do que os do senado. A variável sobre-representação na câmara é muito mais robusta quando comparada com o desempenho das outras variáveis que poderiam representar explicações alternativas para as distorções de gastos regionais, principalmente objetivos de políticas públicas voltadas para enfrentar a pobreza ou a privação socioeconômica de estados favorecidos do ponto de vista fiscal. As correlações da Tabela sugerem, na melhor das hipóteses, um impulso moderado de política pública por trás das alocações regionais de transferências federais. Tanto "pobreza" como "renda" mostram uma relação moderada e significativa com distorções de gastos nãodiscricionários, na direção que se esperaria se objetivos de redistribuição e de alívio da pobreza estivessem por trás desses fluxos. A variável "renda", que representa rendas médias mensais de cada estado (medida em dólares), tem uma relação negativa com a medida de distorção de gastos, enquanto a variável "pobreza" tem uma relação positiva. Porém, os gastos discricionários não apresentam uma relação significativa com essas duas variáveis, sugerindo que outros fatores políticos estão por trás da distribuição regional dessas transferências.

Por fim, os dados da Tabela 2 oferecem uma visão interessante da relação entre federalismo realocativo e os aspectos fiscais das economias políticas locais. Eles sugerem que as realidades fiscais locais são moldadas pelas distorções dos gastos federais. A variável "perlocal”, que representa a participação de receitas estaduais totais geradas pela tributação local, mostra uma correlação negativa significativa com as variáveis "fundratio" e "discratio". Isso sugere que os estados que recebem cotas desproporcionais dos fundos federais são também aqueles cujos orçamentos são menos financiados por receitas tributárias locais. Do mesmo modo, como sugerem as relações positivas significativas registradas entre a variável do emprego no setor público ("pubemp") e as medidas de distorção de gastos, são também os estados que têm as maiores participações de funcionários públicos enquanto porcentagem das populações locais. Pode-se presumir que as transferências federais em estados sobre-beneficiados são fontes relativamente importantes de financiamento para as economias dependentes do setor público. Isso proporciona uma visão mais nuançada do interesse que os políticos têm de manter o status quo do federalismo realocativo, um fato que tem implicações para a montagem de coalizões entre governos centrais e estaduais em períodos de reforma econômica. Essa questão é examinada em mais detalhes no estudo de caso da Argentina feito adiante.

Em suma, os resultados apresentados na Tabela 2 apóiam a hipótese de que a sobre-representação legislativa produz distorções nos gastos federais em favor dos territórios sobre-representação. Além disso, eles também dão suporte à proposição de que a sobre-representação na câmara baixa é mais importante do 
que a sobre-representação no senado para explicar as diferenças em níveis de distorção dos gastos. Porém, os resultados podem, no máximo ser considerados sugestivos, pois são correlações individuais, não controlam outras variáveis nem dão uma medida do impacto relativo de variáveis específicas sobre padrões de gastos federais.

As Tabelas 3 e 4 apresentam os resultados de análises de regressão múltipla que incorporam as variáveis que poderiam, por si só, explicar os desvios da norma da proporcionalidade nos padrões de gastos federais. Em essência, elas buscam explorar em que medida as distorções de gastos federais regionais são resultado da sobre-representação ou são conseqüência de políticas públicas destinadas a diminuir as desigualdades socioeconômicas entre os estados. Com respeito à primeira, as análises procuram estabelecer se a sobre-representação no senado ou na câmara baixa responde melhor pelas variações nas distorções dos gastos federais nos sistemas federais de nossa amostra.

Os resultados destas análises são sugestivos. Tanto a sobre-representação como as políticas públicas parecem influenciar a distribuição das transferências federais para os estados. Ao mesmo tempo em que os resultados apresentados na Tabela 4 para as variáveis "pobreza" e "renda" sugerem que as distorções de gastos discricionários não se devem a considerações de políticas públicas redistributivas, o desempenho da variável "pobreza" na Tabela 3 indica que os desvios da proporcionalidade na distribuição de fundos são influenciados parcialmente por níveis de pobreza local para transferências federais nãodiscricionárias. Porém, ambas as Tabelas confirmam que a sobre-representação desempenha o papel mais significativo nos padrões de gastos realocativos, tanto no caso de transferências não-discricionárias como de discricionárias. Além disso, das duas medidas de sobre-representação legislativa, a variável "houseover" supera todas as outras do modelo por uma margem considerável.

Podem-se tirar duas conclusões dessa análise. Em primeiro lugar, a sobrerepresentação territorial em legislaturas nacionais desempenha um papel substancialmente mais importante do que as considerações de política pública na produção de distorções nos gastos federais característica do federalismo realocativo. Sejam os gastos federais governados por fórmulas de distribuição préestabelecidas ou sejam eles discricionários, a sobre-representação territorial é um determinante poderoso da distribuição regional da generosidade federal em relação aos estados. Em segundo lugar, a sobre-representação na câmara baixa é um preditor mais forte das distorções nos gastos federais do que aquela no senado. Por extensão, ela responde por uma parte significativa da variação entre os federalismos realocativo e proporcional nos quatro países de nossa amostra.

Até agora, a análise proporcionou uma visão estatística e superficial da relação entre sobre-representação legislativa e federalismo fiscal em quatro países 
americanos. Nas seções seguintes, oferecemos uma visão mais detalhadas de como a sobre-representação territorial interage com a economia política e com a geografia da montagem de coalizões em um de nossos casos de federalismo realocativo, a Argentina entre 1990 e 1995.

\section{Tabela 3}

Sobre-representação, pobreza e distorção dos gastos federais Transferências não-discricionárias (análise de regressão múltipla)

\begin{tabular}{|c|c|c|}
\hline Variáveis ind. & Modelo 1 & Modelo 2 \\
\hline \multirow[t]{2}{*}{ (Constante) } & $-0.216^{*}$ & $-0.813^{\star \star}$ \\
\hline & $(0.093)$ & $(0.233)$ \\
\hline \multirow[t]{2}{*}{ Houseover (In) } & $1.019^{* *}$ & $0.872^{* *}$ \\
\hline & $(0.110)$ & $(0.113)$ \\
\hline \multirow[t]{2}{*}{ Senover (In) } & $0.187^{\star *}$ & $0.236^{\star *}$ \\
\hline & $(0.043)$ & $(0.043)$ \\
\hline \multirow[t]{2}{*}{ Pobreza } & $0.009^{\star *}$ & $0.015^{\star *}$ \\
\hline & $(0.003)$ & $(0.003)$ \\
\hline \multirow[t]{2}{*}{ Renda } & 0.00000047 & 0.00026 \\
\hline & $(0.000)$ & $(0.000)$ \\
\hline \multirow[t]{2}{*}{ Argentina } & & $0.659^{* *}$ \\
\hline & & $(0.183)$ \\
\hline \multirow[t]{2}{*}{ Brasil } & & 0.334 \\
\hline & & $(0.241)$ \\
\hline \multirow[t]{2}{*}{ México } & & $0.368^{*}$ \\
\hline & & $(0.402)$ \\
\hline \multirow[t]{2}{*}{$R^{2}$ ajustado } & 0.645 & 0.683 \\
\hline & $(0.425)$ & $(0.402)$ \\
\hline $\mathbf{F}$ & 60.11 & 41.02 \\
\hline $\mathbf{N}$ & 130 & 130 \\
\hline
\end{tabular}

Valores registrados são os coeficientes b (não standardizados). Erros padrões das estimativas mostrados entre parênteses.

** Significativo no nível 0.01 (bicaudal)

* Significativo no nível 0.05 (bicaudal) Variável dependente: "fundratio"= razão da participação percentual do estado dos fundos federais para sua participação percentual da população nacional.

$\mathrm{N}=131$ 


\section{Tabela 4}

Sobre-representação, pobreza e distorção nos gastos federais

Transferências discricionárias.

(análise de regressão múltipla)

Argentina, México e USA

\begin{tabular}{|c|c|c|}
\hline Variáveis ind. & Modelo 1 & Modelo 2 \\
\hline \multirow[t]{2}{*}{ (Constante) } & $-0.435^{\star \star}$ & $-1.497^{\star *}$ \\
\hline & $(0.127)$ & $(0.265)$ \\
\hline \multirow[t]{2}{*}{ Houseover (In) } & $1.541^{* *}$ & $1.091^{* *}$ \\
\hline & $(0.172)$ & $(0.179)$ \\
\hline \multirow[t]{2}{*}{ Senover (In) } & $0.136^{*}$ & $0.211^{* *}$ \\
\hline & $(0.054$ & $(0.051)$ \\
\hline \multirow[t]{2}{*}{ Pobreza } & 0.0014 & 0.003 \\
\hline & $(0.005)$ & $(0.004)$ \\
\hline \multirow[t]{2}{*}{ Renda } & $0.00026^{*}$ & $0.00082^{* *}$ \\
\hline & $(0.000)$ & $(0.000)$ \\
\hline \multirow[t]{2}{*}{ Argentina } & & $1.084^{* *}$ \\
\hline & & $(0.216)$ \\
\hline \multirow[t]{2}{*}{ México } & & $0.545^{\star *}$ \\
\hline & & $(0.167)$ \\
\hline \multirow[t]{2}{*}{$R^{2}$ ajustado } & 0.556 & 0.641 \\
\hline & 33.19 & 31.71 \\
\hline $\mathbf{F}$ & 103 & 103 \\
\hline $\mathbf{N}$ & & \\
\hline
\end{tabular}

Valores registrados são os coeficientes b (não padronizados). Erros-padrão das estimativas mostrados entre parênteses.

** Significativo no nível 0.01 (bicaudal)

* Significativo no nível 0.05 (bicaudal)

Variável dependente: "discratio"= razão da participação percentual do estado nas transferências discricionárias federais para sua participação percentual da população nacional. 


\section{Territórios sobre-representados, gastos discricionários e política eleitoral na Argentina ${ }^{12}$}

A maior parte da população da Argentina e de sua estrutura produtiva está localizada na grande e fértil planície conhecida como região dos Pampas no seu entorno. Buenos Aires, a maior cidade da Argentina, é um distrito federal incrustado na província de Buenos Aires, de grande riqueza agrícola. A cidade está cercada por um enorme cinturão industrial e urbano, o que faz da região da Grande Buenos Aires o centro econômico e populacional do país ${ }^{13}$. Além disso, a região urbana da Grande Buenos Aires é uma das extremidades de uma cadeia de cidades industriais que se estende até a cidade de Rosário, na província vizinha de Santa Fé, e até Córdoba, capital da província de mesmo nome. Juntas, essas três províncias respondem por $73 \%$ da produção industrial total e $65 \%$ da população do país. Se acrescentarmos Mendoza, a quarta província mais próspera e urbanizada, a participação total da produção industrial e da população das "províncias metropolitanas" sobe para 78 e $70 \%$ respectivamente ${ }^{14}$.

Como foi mencionado nas seções anteriores, o sistema federal argentino sobre-representa os territórios pobres e menos populosos mais do que a maioria dos sistemas federais do mundo. Em 1995, as dezenove províncias da "região periférica" do país continham 30\% da população nacional, mas detinham 40 dos 48 assentos do Senado - 83\% do total. Essa sobre-representação estende-se também para a Câmara de Deputados, onde as províncias da região periférica detêm $52 \%$ das cadeiras.

A Constituição argentina de 1856 estabeleceu que os assentos da Câmara de Deputados seriam distribuídos proporcionalmente à população distrital. Porém, esse princípio foi abandonado no século $\mathrm{XX}$, quando tanto o governo peronista como os militares, cada um por seus próprios motivos políticos, introduziram emendas que aumentaram a representação na Câmara das regiões periféricas tradicionalmente conservadoras. O primeiro afastamento da representação proporcional aconteceu em 1949, quando uma constituição escrita pelo governo de Juan Perón estabeleceu um mínimo de dois deputados por província, independentemente da população. Em 1972, o número mínimo foi elevado para três (Sawers, 1996). Em 1983, antes de deixar o governo, o general Reynaldo Bignone aumentou esse número para cinco deputados por província. Em conseqüência, um candidato ao Congresso da cidade de Buenos Aires precisa

\footnotetext{
${ }^{12}$ Uma parte do material apresentado nesta seção foi publicada anteriormente em Gibson e Calvo, 2000.

${ }^{13}$ Com uma população de quase 11 milhões, a Grande Buenos Aires abriga um terço da população nacional.

${ }^{14}$ Nesta seção, dividimos a Argentina em uma região "metropolitana", que compreende as cinco províncias mais desenvolvidas e populosas - Buenos Aires, Distrito Federal, Santa Fé, Córdoba e Mendoza -, e uma região "periférica", que abrange as outras dezenove províncias. Os dados populacionais são tirados de Instituto Nacional de Estadísticas y Censo, 1991 e os dados econômicos são de de Instituto Nacional de Estadísticas y Censo, 1994).
} 
conquistar quase sete vezes mais votos do que seu colega da Terra do Fogo (Cabrera e Murillo, 1994).

Essa sobre-representação institucional significou que nenhuma coalizão nacional eleitoral vencedora ou legislativa poderia ser montada sem o apoio das estruturas regionais de poder na periferia. Tendo em vista os contextos eleitorais altamente disputados nas regiões mais desenvolvidas e urbanizadas, o partido nacional que vencesse eleitoralmente seria aquele que possuísse laços institucionais com as redes de agentes do poder regional capazes de garantir o voto no "interior" do país. O partido que se revelou mais eficiente nisso depois dos anos quarenta foi o peronista. A aparente invencibilidade do peronismo nas urnas - o que veio a ser conhecido tanto pelos partidários como pelos detratores como a "lei de ferro" das eleições argentinas - não se devia aos trabalhadores organizados das metrópoles, mas a seus laços com redes de poder clientelistas e tradicionais e à mobilização eleitoral na periferia ${ }^{15}$.

O papel destacado das províncias periféricas sobre-representadas na coalizão peronista nacional continua até hoje e, durante o primeiro mandato do presidente Menem, elas proporcionaram uma base essencial de apoio na legislatura nacional. Ademais, o peso político da região periférica na coalizão governamental de Menem aumentou graças à coalizão do partido peronista com partidos conservadores provinciais. Esses partidos desempenham um papel importante na política local de várias províncias e, ainda neste período, tornaram-se parceiros plenos no governo, ocupando altas posições na administração, formando blocos a seu favor no Congresso e endossando a candidatura à reeleição do presidente em 1995.

Como podemos ver na Tabela 5, o Partido J usticialista (peronista) controlou a parte do leão das cadeiras das províncias não-metropolitanas no Senado. Essa maioria transformou-se em controle direto em razão da aliança dos peronistas com partidos conservadores das províncias. A combinação de senadores peronistas e senadores de partidos provinciais deu efetivamente ao presidente Menem uma maioria de $78 \%$ dos assentos no Senado.

\footnotetext{
${ }^{15}$ Para uma discussão mais detalhada, ver Gibson, 1997.
} 
Tabela 5

Composição do Senado argentino, 1992-95

\begin{tabular}{|l||c||c||c||c||}
\hline & Região metrop. & Não-metrop. & Total & \% de cadeiras \\
\hline \hline Partido Justicialista & 5 & 25 & 30 & $63 \%$ \\
\hline Partido Radical & 5 & 6 & 11 & $23 \%$ \\
\hline \hline Partidos provinciais & 0 & 7 & 7 & $15 \%$ \\
\hline \hline Total & 10 & 38 & 48 & $101 \%^{*}$ \\
\hline
\end{tabular}

*Não soma $100 \%$ devido a arredondamentos.

Fonte: Dirección de Información Parlamentaria, Congresso Nacional Argentino

(http://proyectos.senado.gov.ar/images/historico/historico.html)

Na Câmara de Deputados, a sobre-representação das províncias menores concedeu também uma vantagem à região periférica sobre as províncias metropolitanas. Com 30\% da população, as províncias periféricas detinham 45\% dos assentos. Como podemos ver na Tabela 6, essa sobre-representação, associada à força do partido peronista nessas regiões, funcionou a favor do peronismo no governo Menem.

O partido peronista dominava os outros partidos tanto nas delegações metropolitanas como não-metropolitanas da Câmara de Deputados. Contudo, sua quase maioria devia muito a sua vantagem às cadeiras das províncias periféricas. $\mathrm{O}$ partido governante controlava $51 \%$ dos assentos dessas províncias, em comparação com $48 \%$ das cadeiras das províncias metropolitanas. Ademais, era nas regiões periféricas que a aliança peronista com partidos conservadores provinciais dava ao partido governante o controle do órgão legislativo. Juntos, peronistas e partidos provinciais controlavam 70 \% da delegação não-metropolitana na Câmara de Deputados, em comparação com os $54 \%$ controlado pelo bloco peronista-conservador das províncias metropolitanas. Em suma, mesmo na Câmara de Deputados, a coalizão periférica dava maior alavancagem política ao partido governante do que o tamanho de sua população indicaria. Com 30\% do eleitorado, as províncias periféricas davam à aliança entre peronistas e partidos provinciais um total de setenta cadeiras na Câmara. A região metropolitana, com $70 \%$ do eleitorado, dava um total de setenta e sete assentos.

De que modo essa estrutura regional da coalizão do partido peronista influenciou a gestão da reforma econômica entre 1990 e 1995? Em essência, ela fez com que o governo Menem protegesse as regiões periféricas politicamente sobre-representadas dos efeitos mais devastadores das reformas. Ao mesmo tempo, levava o ajuste de contas para as regiões metropolitanas do país. Essa meta foi atingida por meio da postergação dos cortes de funcionários nos setores públicos provinciais e do aumento de fluxos de subsídios do governo central para 
os cofres públicos provinciais e o que possibilitou a estratégia de manter o nível de emprego público nas províncias. Tratamos em seguida dos padrões regionais de gastos do governo federal ${ }^{16}$.

Tabela 6

Composição da Câmara de Deputados Argentina, 1993-1995

\begin{tabular}{|l||c||c|c|c||}
\hline & Região metrop. & Não-metrop. & Total & Porcentagem \\
\hline \hline P. Justicialista & 69 & 59 & 128 & $50 \%$ \\
\hline \hline P. Radical & 49 & 34 & 83 & $32 \%$ \\
\hline \hline Conservadores/ & 8 & 21 & 29 & $11 \%$ \\
\hline Outros provinciais & 16 & 1 & 17 & $7 \%$ \\
\hline \hline Total & 142 & 115 & 257 & $100 \%$ \\
\hline \hline
\end{tabular}

Fonte: Fraga

A transferência de recursos do governo federal aos governos provinciais ocorre principalmente através de dois canais. O primeiro é um mecanismo de partilha das receitas tributárias nacionais, conhecido como "co-participação", que favorece sistematicamente as províncias periféricas de acordo com uma fórmula automática de partilha das receitas. O segundo é um feixe de fluxos discricionários que inclui contribuições do tesouro nacional aos governos provinciais, um fundo para ajudar as províncias com "desequilíbrio fiscal" e subsídios e créditos federais para habitação, obras públicas, saúde e educação ${ }^{17}$.

\footnotetext{
${ }^{16}$ Entre 1990 e 1994, o governo Menem cortou substancialmente empregos no setor público, mas esses empregos eram do setor público nacional, $80 \%$ de cujos empregados estavam localizados em regiões metropolitanas. O setor público provincial não foi tocado e, na verdade, aumentou levemente entre 1990 e 1995. Para um tratamento mais detalhado do tema, ver Gibson e Calvo, 2000.

${ }^{17}$ Para detalhes sobre os esquemas de partilha de receitas com as províncias, ver Inter-American Development Bank, 1994 e World Bank, 1993. A última modificação da fórmula de participação, efetuada em 1988, colocou o grosso da transferência de recursos dentro da categoria de fundos "co-participados" e reduziu o componente de fluxo discricionário do total das transferências federais.
} 
Federalismo realocativo: Sobre-representação legislativa e gastos públicos no hemisfério ocidental

Tabela 7

Gastos federais e emprego público por província

\begin{tabular}{|c|c|c|c|c|c|c|}
\hline Província & $\begin{array}{c}\text { \% do orçamento } \\
\text { provincial } \\
\text { financiado pelo } \\
\text { Governo Fed.. } 1994 \\
\end{array}$ & $\begin{array}{l}\text { Total de transf. } \\
\text { federais } 1990 \\
\text { (milhões US\$) }\end{array}$ & $\begin{array}{c}\text { Total de } \\
\text { transf. } \\
\text { federais1995 } \\
\text { (milhões US\$) }\end{array}$ & $\begin{array}{c}\text { Transferências } \\
\text { federais: } \\
\text { dólares per } \\
\text { Capita } 1995 \\
\end{array}$ & $\begin{array}{l}\text { Transferências } \\
\text { discricionárias } \\
1990 \text { (milhões } \\
\text { US\$) } \\
\end{array}$ & $\begin{array}{l}\text { Transferências } \\
\text { discricionárias } \\
1995 \text { (milhões } \\
\text { US\$) } \\
\end{array}$ \\
\hline Distrito Federal ${ }^{*}$ & 6.16 & & & & & \\
\hline Buenos Aires & 46.04 & 1,292 & 3,544 & 282 & 164 & 290 \\
\hline Córdoba & 55.16 & 514 & 1,007 & 363 & 63 & 68 \\
\hline Mendoza & 58.57 & 306 & 611 & 432 & 25 & 37 \\
\hline Santa Fé & 52.28 & 989 & 2,031 & 725 & 104 & 97 \\
\hline Metrop. (média) & 43.64 & 775 & 1,798 & 451 & 89 & 123 \\
\hline Catamarca & 90.88 & 198 & 339 & 1282 & 53 & 30 \\
\hline Corrientes & 85.71 & 260 & 501 & 709 & 65 & 70 \\
\hline Chaco & 87.97 & 311 & 596 & 1105 & 69 & 70 \\
\hline Chubut & 79.98 & 182 & 395 & 629 & 40 & 99 \\
\hline Entre Rios & 70.74 & 306 & 638 & 625 & 58 & 62 \\
\hline Formosa & 92.44 & 235 & 497 & 1247 & 53 & 99 \\
\hline Jujuy & 74.46 & 303 & 392 & 765 & 153 & 54 \\
\hline La Pampa & 62.59 & 124 & 302 & 1161 & 21 & 67 \\
\hline La Rioja & 84.04 & 172 & 530 & 2401 & 51 & 259 \\
\hline Misiones & 82.35 & 220 & 468 & 593 & 52 & 72 \\
\hline Neuquén & 68.55 & 359 & 608 & 1563 & 66 & 123 \\
\hline Rio Negro & 66.16 & 289 & 401 & 791 & 111 & 74 \\
\hline Salta & 71.14 & 271 & 535 & 617 & 34 & 64 \\
\hline San Juan & 82.97 & 214 & 449 & 849 & 41 & 64 \\
\hline San Luis & 76.19 & 159 & 321 & 1120 & 41 & 56 \\
\hline Santa Cruz & 76.30 & 224 & 426 & 2665 & 43 & 97 \\
\hline Stgo. del Estero & 85.63 & 243 & 548 & 815 & 43 & 89 \\
\hline $\begin{array}{l}\text { Tierra del } \\
\text { Fuego** }\end{array}$ & 71.58 & 90 & 236 & 3402 & 33 & 92 \\
\hline Tucumán & 76.42 & 323 & 613 & 536 & 62 & 58 \\
\hline $\begin{array}{l}\text { Periferia } \\
\text { (média) }\end{array}$ & 78.22 & 235 & 463 & 1204 & 57 & 84 \\
\hline
\end{tabular}

*O Distrito Federal não é uma província e não participa dos programas de partilha da receita federal.

Fontes: dados de 1990, INDEC, 1991; dados de 1994, Ministério da Economia, 1995; dados sobre desemprego, INDEC, 1995; dados eleitorais calculados a partir de dados fornecidos pelo Ministério do Interior.

Como os dados da Tabela 7 mostram, as transferências federais totais para 
as províncias mais do que dobraram entre 1990 e $1995^{18}$. Porém, os fluxos automáticos de partilha de receitas não foram os únicos desembolsos que aumentaram durante esse período. Os fluxos discricionários também se mantiveram no mesmo ritmo, quase dobrando entre 1990 e $1995^{19}$. Ao mesmo tempo em que os fundos federais são importantes para todas as províncias, a maior dependência das economias da região periférica do estado nacional pode ser vista na Tabela 7, que contrasta os padrões de subsídios nas províncias metropolitanas e periféricas. O total dos gastos públicos de cada província metropolitana é muito maior do que o das províncias da região periférica, mas estas têm uma parcela muito maior de seus orçamentos subsidiada pelo governo federal. Uma média de aproximadamente $43 \%$ dos orçamentos das províncias metropolitanas é subsidiada pelo governo federal, principalmente por meio do mecanismo institucional de co-participação. Em contraste, 78\% das despesas das províncias periféricas são financiados pelo governo nacional. Ainda neste caso, os fundos discricionários representam $18 \%$ do total de subsídios federais, contrastando com os $7 \%$ da região metropolitana ${ }^{20}$.

Esses dados fornecem ainda uma indicação das dimensões políticas dos gastos discricionários com as províncias durante o governo Menem e do lucro político potencialmente maior para o partido governante de cada dólar gasto na manutenção do eleitorado da periferia. Em termos absolutos, as transferências federais para as províncias metropolitanas, superam em muito aquelas para as províncias periféricas (Tabela 7). Porém, os dados de gastos per capita da Tabela 8 mostram quão favorecidas são as populações que vivem na periferia pelos esquemas de transferências federais. O governo federal gastou, em média, três vezes mais por pessoa na periferia do que na metrópole.

Se olharmos para os padrões de financiamento discricionário politicamente mais determinados, vemos também uma clara inclinação para a periferia dos gastos do governo peronista durante o período. As transferências discricionárias aumentaram nas duas regiões, mas a taxa de crescimento da periferia foi bem mais do que o dobro daquela das províncias metropolitanas. Ademais, os números da

\footnotetext{
${ }^{18}$ Esse aumento foi, em larga medida, um benefício ao setor público provincial das reformas nacionais levadas a cabo pelo governo Menem, notadamente um aumento substancial na coleta de tributos federais durante os primeiros anos do governo. Isso significou que, de acordo com a fórmula de partilha automática da receita fiscal estabelecida em 1988 pelo governo anterior do presidente Alfonsín, as transferências "co-participadas" aos governo provinciais aumentariam muito no começo dos anos 90 .

${ }^{19}$ Em conseqüência do aumento de fundos federais, as finanças públicas periclitantes das províncias melhoraram um pouco. Porém, os fluxos maiores constituíram um grande desincentivo às reformas do setor público provincial, evitadas por seus governos no primeiro mandato de Menem. Ver World Bank, 1993 a 1996. Em 1992, o governo Menem transferiu as funções de educação e saúde do governo nacional para as províncias, o que aumentou o fardo fiscal delas e contrabalançou uma parte do aumento dos fluxos de receitas. Porém, o aumento na partilha das receitas representou mais do que o dobro da despesa com serviços transferida às províncias (Sawers, 1996).

${ }^{20}$ De acordo com uma fonte, quase $70 \%$ dos gastos públicos nas províncias periféricas vão para o salário dos funcionários, em comparação com $55 \%$ nas províncias metropolitanas (Sawers, 1996).
} 
Tabela 8 mostram o impacto local substancialmente maior que os gastos discricionários causaram nas províncias periféricas. Em 1995, a média das quantias per capita transferidas para as províncias periféricas foi dez vezes maior do que aquela destinada às províncias metropolitanas. Além disso, ainda conforme sugerem os números da Tabela 8, o lucro político potencial desses gastos para a coalizão legislativa do partido governante foi amplificado pelo custo relativamente baixo em votos exigido para eleger um membro do congresso na periferia.

Por fim, a Tabela 8 oferece uma rápida visão dos benefícios políticos potenciais do subsídio do governo Menem aos orçamentos dos governos provinciais. As províncias da periferia relativamente mais subsidiadas, mas menos caras, experimentaram aumentos no desemprego menores do que as províncias metropolitanas menos subsidiadas. 
OPINIÃO PÚBLICA, Campinas, Vol. IX, nำ1, 2003, pp. 98-123

Tabela 8

Transferências federais, desemprego e votos

\begin{tabular}{|c|c|c|c|c|c|c|}
\hline & $\begin{array}{c}\text { Transferências } \\
\text { discricionárias } \\
\text { federais: } \\
\text { dólares per } \\
\text { capita } \\
1995\end{array}$ & $\begin{array}{c}\text { Razão: eleitores } \\
\text { necessários para } \\
\text { eleger um membro } \\
\text { do Congresso } \\
\text { sobre a média } \\
\text { nacional } \\
\text { (1=média nac.) } \\
\end{array}$ & $\begin{array}{c}\text { Crescimento } \\
\text { percentual em } \\
\text { transferências } \\
\text { discricionárias, } \\
\text { 1990-1995 }\end{array}$ & $\begin{array}{c}\text { Crescimento } \\
\text { do } \\
\text { desemprego: } \\
\text { 1989-1995 }\end{array}$ & $\begin{array}{c}\text { Porcentagem do } \\
\text { voto } \\
\text { presidencial } \\
\text { peronista } \\
1995\end{array}$ & $\begin{array}{c}\text { Mudança no } \\
\text { voto } \\
\text { presidencial } \\
\text { peronista } \\
1989-1995\end{array}$ \\
\hline Distrito Federal & & & & 9.10 & 41.5 & 5.20 \\
\hline Buenos Aires & 23.03 & 1.75 & 76 & 12.60 & 51.8 & 1.90 \\
\hline Córdoba & 24.58 & 1.74 & 7 & 6.40 & 48.2 & 3.60 \\
\hline Mendoza & 26.02 & 1.53 & 48 & 2.40 & 52 & 9.90 \\
\hline Santa Fé & 34.66 & 1.75 & -7 & 6.50 & 46.8 & -4.80 \\
\hline Metrop. (média) & 27.07 & 1.69 & $31 \%$ & 7.40 & 48.38 & 3.16 \\
\hline Catamarca & 113.54 & .52 & -43 & 2.00 & 52.3 & -3.60 \\
\hline Corrientes & 87.98 & 1.16 & 0 & 7.20 & 46 & 3.90 \\
\hline Chaco & 83.37 & .66 & 147 & 4.10 & 56.8 & 5.10 \\
\hline Chubut & 277.16 & 1.14 & 8 & 2.90 & 57 & 14.40 \\
\hline Entre Rios & 60.77 & 1.19 & 7 & 2.80 & 46.2 & -5.40 \\
\hline Formosa & 248.49 & .9 & 87 & -3.80 & 49.5 & -8.50 \\
\hline Jujuy & 105.40 & .75 & -64 & 5.60 & 44.2 & 1.10 \\
\hline La Pampa & 257.70 & .56 & 220 & 2.30 & 50.3 & -1.20 \\
\hline La Rioja & 1173.38 & .44 & 407 & 5.20 & 76.1 & 9.50 \\
\hline Misiones & 91.26 & 1 & 38 & 3.50 & 49.5 & -3.20 \\
\hline Neuquen & 316.33 & 1.18 & 86 & 8.10 & 53.5 & 14.30 \\
\hline Rio Negro & 146.02 & .85 & -33 & 3.70 & 44 & -3.20 \\
\hline Salta & 73.89 & 1.14 & 88 & 10.60 & 54.1 & 12.90 \\
\hline San Juan & 121.05 & .88 & 56 & 5.20 & 59.8 & 11.40 \\
\hline San Luis & 195.49 & .6 & 37 & 3.20 & 51.7 & 5.40 \\
\hline Santa Cruz & 606.86 & .35 & 126 & 2.40 & 58.4 & 3.70 \\
\hline $\begin{array}{l}\text { Stgo. del } \\
\text { Estero }\end{array}$ & 132.44 & .95 & 107 & .00 & 64.6 & -.30 \\
\hline $\begin{array}{l}\text { Tierra del } \\
\text { Fuego }\end{array}$ & 1326.24 & .15 & 179 & -.20 & 61.1 & 18.40 \\
\hline Tucumán & 50.78 & 1.42 & -6 & 7.30 & 45.5 & 4.20 \\
\hline $\begin{array}{l}\text { Periferia } \\
\text { (média) }\end{array}$ & 288.78 & .83 & $76 \%$ & 3.79 & 53.37 & 7.63 \\
\hline
\end{tabular}


Quão significativo foi, no entanto, esse investimento político dos gastos públicos na periferia sobre-representada para a capacidade do governo Menem de manter uma coalizão legislativa vencedora durante o período de reforma econômica? As análises de regressão exibidas nas Tabelas 9 e 10 tentam responder essa questão. Em primeiro lugar, buscamos identificar as causas potencias das mudanças nos padrões de gastos discricionários regionais apresentados nas Tabelas 7 e 8. Presumimos, de acordo com a hipótese de trabalho deste artigo, que a sobre-representação afetou a distribuição estratégica de fundos discricionários pelo governo central. Porém, pressupomos também que os gastos discricionários procuraram recompensar ou favorecer os partidários provinciais do governo central e que os resultados de eleições anteriores (especificamente, o desempenho do partido peronista) também afetaram o fluxo de fundos discricionários para as províncias.

O modelo da Tabela 9 inclui assim a sobre-representação territorial na Câmara de Deputados ("houseover") e o total de votos do partido peronista na eleição presidencial de 1989 e nas eleições de 1991 para a Câmara de Deputados ("PJ 89pres" e "PJ 91house" respectivamente). Os resultados sugerem que, embora o fluxo de fundos discricionários tenha sido de fato afetado pelo resultado das eleições anteriores, a sobre-representação foi um preditor mais forte da alocação de fundos discricionários do que o desempenho eleitoral do partido peronista. Isto é, ao mesmo tempo em que os dirigentes do partido peronista local colheriam provavelmente os frutos da generosidade do governo central se apresentassem um bom desempenho eleitoral, eles provavelmente também veriam mais dessa generosidade se vivessem em províncias sobre-representadas.

$\mathrm{Na}$ segunda análise de regressão (Tabela 10), buscamos captar o impacto das mudanças dos gastos discricionários sobre o desempenho eleitoral do partido peronista nas eleições de 1995 para a Câmara de Deputados. Tendo por suposto que o desempenho eleitoral anterior afeta os resultados eleitorais subseqüentes, o modelo incorpora uma variável que mede o desempenho do partido em eleições legislativas anteriores ${ }^{21}$. Além disso, o modelo incorpora uma variável econômica contextual, as mudanças nos níveis de desemprego provincial, para controlar seu impacto no desempenho eleitoral peronista ${ }^{22}$.

\footnotetext{
${ }^{21}$ A eleição anterior usada no modelo é a de 1991. Teria sido melhor utilizar a eleição de 1993, mas não temos no momento dados dessa eleição.

${ }^{22} \mathrm{O}$ desemprego subiu para níveis sem precedentes históricos durante o primeiro mandato de Menem. Pode-se dizer que foi a questão mais importante discutida publicamente durante as eleições de 1995.
} 
OPINIÃO PÚBLICA, Campinas, Vol. IX, nำ1, 2003, pp. 98-123

\section{Tabela 9}

Sobre-representação, eleições e mudanças nos gastos discricionários (análise de regressão múltipla)

\begin{tabular}{||l||c||c||c||c|c||}
\hline \multicolumn{1}{|c|}{ Modelo } & B & Erro estand. & Beta & t & Sig. \\
\hline \hline (Constante) & -361.882 & 122.441 & & -2.956 & .008 \\
\hline Houseover & 24.604 & 9.157 & .440 & 2.687 & .015 \\
\hline \hline PJ89pres. & 4.276 & 2.327 & .310 & 1.837 & .082 \\
\hline \hline PJ91house & 4.253 & 1.845 & .390 & 2.305 & .033 \\
\hline
\end{tabular}

$\mathrm{N}=22 ; \mathrm{R}^{2}$ ajustado=.412; $\quad$ Erro estandardizado $=78.702$

Variável dependente: mudança nos gastos discricionários, por província, 1990-95

Tabela 10

Gastos discricionários federais, desemprego e a eleição de 1995 para a Câmara de Deputados (análise de regressão múltipla)

\begin{tabular}{||l||c||c||c||c||c||}
\hline \multicolumn{1}{|c|}{ Modelo } & B & Erro estand. & Beta & t & Sig. \\
\hline \hline (Constante) & 27.134 & 8.76 & & 3.1 & .006 \\
\hline \hline Chdisc & .051 & .020 & .429 & 2.6 & .019 \\
\hline \hline PJ91house & .482 & .215 & .372 & 2.2 & .037 \\
\hline Desemeprego Ch. & .923 & .510 & -.270 & 1.8 & .086 \\
\hline \hline
\end{tabular}

$\mathrm{N}=22 ; \quad \mathrm{R}^{2}$ ajustado=.519; $\quad$ Erro estand. $=8.5$

Variável dependente: porcentagens de voto peronista, eleição para a Câmara de Deputados de 1995

Os resultados sugerem que o impacto relativo mais forte sobre o desempenho eleitoral peronista nas eleições legislativas de 1995 veio dos aumentos em gastos discricionários para as províncias. Levando em conta as duas análises de regressão, podemos inferir que desembolsos federais estrategicamente localizados para províncias sobre-representadas desempenharam um papel importante na manutenção da coalizão legislativa do presidente Menem durante o período de reforma do mercado. Ou seja, a turbulência na metrópole tornou-se politicamente suportável graças aos gastos federais na periferia sobre-representada.

\section{Conclusão}

Este artigo indicou que a sobre-representação territorial afeta a distribuição regional das transferências fiscais do governo central em sistemas federais. As provas apresentadas sustentam nossa hipótese de que essa sobre-representação 
promove a realocação de fundos partilhados da receita federal e de gastos discricionários que beneficiam estados sobre-representados. Porém, observamos também variações nessa relação em diferentes sistemas federais: alguns governos distribuem fundos aos estados de modo proporcional à população e outros não. Introduzimos então uma distinção conceitual entre "federalismo realocativo" e "federalismo proporcional" para captar essa divergência.

Dentre os países apresentados, Brasil e Argentina foram classificados como casos de "federalismo realocativo", enquanto Estados Unidos e México foram considerados casos de "federalismo proporcional". Buscamos também examinar as possíveis razões para essa divergência nos quatro países. A análise de dados agrupados de todos os países sobre os padrões de gastos federais, alocação de assentos no legislativo e fatores socioeconômicos levou à conclusão de que a sobrerepresentação na câmara baixa do Congresso é a melhor explicação para a variação entre nossos casos de federalismo realocativo e proporcional. A Câmara de Deputados, e não o Senado, é a força propulsora por trás da realocação das transferências federais em favor de estados e províncias sobre-representadas.

Esse resultado vai contra pressupostos amplamente aceitos sobre o papel central do senado na implementação de características não-proporcionais dos sistemas federais. Ele sugere que é preciso dar mais atenção aos efeitos da sobrerepresentação na câmara baixa em relação às políticas públicas nos sistemas federais ${ }^{23}$. O senado, na função de órgão constitucionalmente sancionado da representação territorial, ficou com a parte do leão da atenção dos estudiosos do tema ${ }^{24}$. Os resultados deste estudo sugerem que a sobre-representação no senado per se é uma variável explicativa fraca para as variações de gastos entre os sistemas federais que analisamos, cuja maioria contém um elemento significativo de sobrerepresentação territorial em seus senados ${ }^{25}$.

Os resultados deste estudo também apontam para uma questão que aqui foi tratada apenas parcialmente: quais são os mecanismos causais por trás da relação entre sobre-representação e distorções nos gastos federais? A análise comparativa de nossos quatro casos estabeleceu associações sem explorar os mecanismos causais, mas nosso estudo de caso da Argentina proporcionou alguns esclarecimentos sobre essa questão. Com respeito às transferências estratégicas e clientelistas, nosso estudo de caso da Argentina ofereceu uma visão da lógica

\footnotetext{
${ }^{23}$ A importância dessa sugestão parece ainda maior tendo em vista o estudo de Snyder e Samuels sobre a prevalência da má proporcionalidade nas câmaras baixas em todos os sistemas federais e unitários da América Latina.

${ }^{24}$ Por exemplo, o capítulo de Alfred Stepan no volume em que este artigo foi publicado originalmente trata quase exclusivamente do senado em sua mensurações e exame teórico da sobre-representação nos sistemas federais.

${ }^{25}$ Uma possibilidade não explorada neste estudo é a de que a sobre-representação no senado possa ser um preditor mais poderoso em agrupamentos de casos que incluam senados mais proporcionais, como acontece nos sistemas da Alemanha, da Índia e da Áustria. Esses órgãos sobre-representam de fato unidades subnacionais, mas eles não alocam o mesmo número de cadeiras do senado a todos os estados. Seria muito interessante um estudo comparativo das políticas fiscais que incluísse sistemas federais com senados estruturados de forma mais proporcional.
} 
causal do federalismo realocativo. Dito de forma simples, os territórios sobrerepresentados tendem a retribuir politicamente os investimentos dos gastos políticos. Isso introduz uma dinâmica de "eleitorado de manutenção barata" que tem implicações para o uso dos fundos públicos na montagem de coalizões (Gibson e Calvo, 2000). Uma vez que o investimento econômico exigido para uma unidade de apoio político de um território sobre-representado é muito mais baixo do que aquele requerido para um território sub-representado e muito populoso, entra em jogo a dinâmica de selecionar entre eleitorados de "manutenção barata" e de "manutenção cara". Na Argentina, o tamanho relativamente pequeno das economias periféricas dependentes do Estado tornou possível o gasto político nessas regiões. Ademais, a sobre-representação política da periferia proporcionou ao partido governante um lucro político substancial com investimentos relativamente pequenos de gastos políticos.

Essa lógica funcionava em um contexto onde o poder executivo nacional desempenhava o papel decisivo na determinação da alocação regional de gastos federais de curto prazo. Porém, em contextos nos quais o legislativo desempenha um papel decisivo, os mecanismos causais serão obviamente diferentes. Isso sugere que o "escopo político" em questões orçamentárias de diferentes organismos governamentais, especificamente a importância relativa do Executivo e do Legislativo na estruturação da distribuição regional dos gastos federais, é um tópico que merece mais pesquisas. Se o Congresso desempenha um papel essencial na determinação desses fluxos, a sobre-representação pode induzir realocações dos gastos federais influenciadas pelo Legislativo, onde os próprios estados sobre-representados efetuam tais realocações graças a sua alavancagem nas comissões de orçamento. David Samuels (2002), por exemplo, mostra em detalhes como os legisladores brasileiros de estados sobre-representados conseguem reproduzir sua sobre-representação nas comissões orçamentárias, induzindo assim realocações de fundos públicos para seus estados. Esse modelo acionado pelo Legislativo contrasta com o modelo acionado pelo Executivo que examinamos na Argentina, onde o governo central direciona os gastos federais aos estados sobre-representados para sustentar sua maioria no Congresso.

Os mecanismos causais de transferências federais definidas pela Constituição, ou partilha de receitas federais de acordo com fórmulas préestabelecidas, merecem também pesquisas mais aprofundadas, pois eles, muito provavelmente, são diferentes daqueles das transferências discricionárias. A pesquisa histórica sobre as negociações que estabeleceram fórmulas de partilha de receitas poderia fornecer esclarecimentos interessantes sobre como o equilíbrio de poder entre o governo central e os estados e entre os próprios estados estruturou os arranjos federais do ponto de vista fiscal. Em contextos de autoridade central forte, ou em contextos de aliança entre o governo federal e os estados prósperos, 
mais arranjos de partilha proporcional das receitas resultariam provavelmente dessas negociações. Desse modo, diferentes configurações de poder e aliança entre os governos central e estaduais, bem como entre os estaduais, iriam oferecer configurações diferentes de partilha das receitas federais.

O mesmo pode ser dito para as origens da sobre-representação da câmara baixa. A sobre-representação é usada ainda como uma medida da "robustez" ou "periferalização" dos sistemas federais ${ }^{26}$, mas isso tergiversa a questão se a sobrerepresentação é resultado ou causa da natureza "periferalizada" dos sistemas federais. Também deixa em aberto a questão de se é obra dos estados ou de um governo central ansioso para recrutar apoio em regiões específicas do país (como foi o caso de Perón e dos líderes militares posteriores na Argentina) ${ }^{27}$.

Em suma, as características institucionais dos sistemas federais fazem sim diferença para a política. A economia política do federalismo não é independente das estruturas políticas dos sistemas federais. Este artigo tentou lançar luz sobre uma dessas áreas de interdependência. Na medida em que as pesquisas sobre federalismo continuem a se desenvolver, esperamos que novas luzes se façam sobre os mecanismos causais que estão por trás dessas relações, bem como sobre sua significação para a política e o desenvolvimento político.

\footnotetext{
${ }^{26}$ Ver, por exemplo, os artigos de Samuels e Mainwaring (2003) e Stepan(2003) no volume em que este trabalho foi publicado originalmente.

${ }^{27}$ Para algumas respostas a essas questões, ver o capítulo de Snyder e Samuels no volume em que este artigo foi publicado originalmente.
} 


\section{BIBLIOGRAFIA}

CABRERA, Ernesto e María Victoria Murillo. 1994. "The 1993 Argentine Elections". Electoral Studies $13(2)$.

DIRECCIÓN DE INFORMACIÓN PARLAMENTARIA, Congresso Nacional Argentino. http://proyectos.senado.gov.ar/images/historico/historico.html.

GIBSON, Edward L. 1997. "The Populist Road to Market Reform: Policy and Electoral Coalitions in Mexico and Argentina". World Politics 59 (3).

GIBSON, Edward L. e Ernesto Calvo. 2000. "Federalism and Low-Maintenance Constituencies: Territorial Dimensions of Economic Reform in Argentina". Studies in Comparative International Development 35 (3).

IBGE. http://www.ibge.gov.br.

INDEC. 1997. Anuario Estadístico 1997. Buenos Aires: INDEC.

INEGI. 1995. Anuario Estadistico de los Estados Unidos Mexicanos. Cidade do México: INEGI.

INSTITUTO FEDERAL ELECTORAL. 1997. The Mexican Electoral System and the Federal Election. México: Instituto Federal Electoral.

INSTITUTO NACIONAL DE ESTADÍSTICAS Y CENSO (INDEC). 1994. Censo Nacional Económico. Buenos Aires: INDEC.

INSTITUTO NACIONAL DE ESTADÍSTICAS Y CENSO (INDEC), Ministerio de Economía y Obras y Servicios Públicos. 1991. Censo nacional de población y vivienda. Buenos Aires: INDEC.

INTER-AMERICAN DEVELOPMENT BANK. 1994. La descentralización fiscal en América Latina, problemas y perspectivas: el caso de Argentina. Washington, D.C.

MAINWARING, Scottand e SAMUELS, David. 2003. Federalism Constraints on the Central Goverment, and Economic Reform in Democratic Brazil”. M. Gibson, E. 2003. Federalism: Latin America in Comparative Perspective, no prelo.

MARVÁN, Ignacio. 1997. "Reflexiones sobre federalismo y sistema político en México". Política y Gobierno IV (1):149-166.

MINISTÉRIO DA FAZENDA. http://www.fazenda.gov.br.

MINISTÉRIO DA ADMINISTRAÇÃO FEDERAL E REFORMA DO ESTADO. 1997. Boletim Estatístico de Pessoal, Julho.

MINISTERIO DE ECONOMÍA Y OBRAS Y SERVICIOS PÚBLICOS. 1994. Situación de las provincias Argentinas: cierre de 1994 y perspectivas para 1995. Buenos Aires: Ministerio de Economía y Obras y Servicios Públicos.

RIKER, William H. 1964. Federalism: Origin, Operation, Significance. Boston: Little Brown. 
- 1975. Federalism. In Handbook of Political Science, editado por F. Greenstein e N. W. Polsby. Reading, MA: Addison-Wesley.

— 1987. The Development of American Federalism. Boston: Kluwer Academic Publishers.

SAMUELS, David. 2002. "Progressive Ambition, Federalism, and Pork-Barreling in Brazil". In Legislative Politics in Latin America, S. Morgenstern e B. Nacif (eds.). Cambridge: Cambridge University Press.

SAMUELS, David e SNYDER, Richard. 2001. "The Value of a Vote: Malapportionment in Comparative Perspective". British Journal of Political Science 31 (4):651-71.

SAWERS, Larry. 1996. The Other Argentina: The Interior and National Development. Boulder: Westview Press.

STEPAN, Alfred. 2001. "Toward a New Comparative Politics of Federalism, (Multi) Nationalism, and Democracy: Beyond Rikerian Federalism". In Arguing Comparative Politics. Oxford: Oxford University Press.

STEPAN, Alfre. 2003. Tamard a new Comparative politics of Federalism and Democracy. Beyond Rikerian Federalism m Gibson, E, 2003. Federalism: Latin America in Comparative Perspective, no prelo.

WORLD BANK. 1993. Argentina: From Insolvency to Growth. A World Bank Country Study. Washington, D.C.: World Bank.

1996. Argentina: Cordoba-Public Sector Assessment and Proposals for Reform. Latin America and Caribbean Regional Office, Washington, D.C.: The World Bank. 